\title{
The Intrauterine Bigatti Shaver for Endometrial Lesions: Our Experience and Modifications
}

\author{
Liying Yang, Hemashree Rajesh, Suling Yu \\ Department of Obstetrics \& Gynaecology, Singapore General Hospital, Singapore City, Singapore \\ Email: yang.liying@sgh.com.sg
}

How to cite this paper: Yang, L.Y., Rajesh, H. and Yu, S.L. (2017) The Intrauterine Bigatti Shaver for Endometrial Lesions: Our Experience and Modifications. Open Journal of Obstetrics and Gynecology, 7, 1-6. http://dx.doi.org/10.4236/ojog.2017.71001

Received: July 22, 2016

Accepted: December 20, 2016

Published: December 23, 2016

Copyright $\odot 2017$ by authors and Scientific Research Publishing Inc. This work is licensed under the Creative Commons Attribution International License (CC BY 4.0).

http://creativecommons.org/licenses/by/4.0/ (c) (i) Open Access

\begin{abstract}
Background: Removal of endometrial polyps and submucosal fibroids by blind avulsion or excision with resectoscope is associated with risks such as fluid imbalance and uterine perforation. This review describes our centre's experience with the intrauterine Bigatti shaver (IBS), a new method for resecting these lesions. Methods: All procedures performed between August 2015 and June 2016 were included. Patient demographics and operation details (set-up time, resection time, operative findings and complications) were collected at time of surgery using a standardised form. Results: 21 cases were performed between August 2015 and June 2016 by two senior gynaecologists. The majority $(18,86 \%)$ were performed for polyps associated with menstrual abnormalities or subfertility. Mean operating time was 9.6 minutes (range 3 - 25), median fluid input $1450 \mathrm{mls}$ (range 700 - 3000) and median fluid deficit $100 \mathrm{mls}$ (range 50 - 300). There were no cases of infection, perforation or fluid overload. The IBS blade was bent after resection of an anterior wall polyp in an anteverted uterus. A $3 \mathrm{~mm}$ grade 1 submucosal fibroid could not be resected as it was too hard in consistency. Conclusions: The constant clear visualisation provided by the continuous flow of fluid enabled fast and complete resection of sizeable polyps with minimal fluid deficit. No serious complications occurred despite this being the initial series performed by both surgeons. Bending of the blade may be avoided by rotating the camera such that the operating channel is situated just next to the lesion. A drainage sock was fashioned out of ribbon gauze and attached to the end of the suction tubing for collection of small polyp fragments. The IBS is a valuable addition to current methods for resection of endometrial polyps. Further study is required to determine its utility for submucosal fibroids, particularly those with a hard consistency.
\end{abstract}

\section{Keywords}

Endometrial Polyps, Submucosal Fibroids, Intrauterine Bigatti Shaver, Hysteroscopic Surgery 


\section{Introduction}

Endometrial polyps and submucosal fibroids may be associated with menorrhagia, inter-menstrual bleeding and subfertility. These lesions are amenable to hysteroscopic surgery, and are traditionally removed by methods such as blind avulsion or excision using a resectoscope or hysteroscopic scissors. These approaches however have risks such as incomplete resection, poor visualisation, fluid imbalance and uterine perforation with serious bowel injury [1] [2].

The intrauterine Bigatti shaver (IBS) is a new method for removing endometrial masses such as polyps and fibroids [3]. It consists of a mechanical shaver that enables complete resection of the polyp to its base, as well as a sheath that allows a continuous inflow of normal saline and outflow of blood and tissue fragments for clear visualisation. This review describes our centre's experience with the device as well as several learning points from our series of cases.

\section{Methods}

All IBS procedures performed between August 2015 and June 2016 were included. Operative data was collected at the time of surgery using a standardized form. This form was designed to collect information on patient demographics (age, indication for surgery), operative data (surgeon, device set-up time, resection time, operative findings, number, size and location of polyps or fibroids) and surgical complications (technical problems, bleeding, infection, uterine perforation, incomplete resection, fluid overload and others). Device set-up time was defined as time taken to completely assemble the instrument, while resection time was defined as the time from the introduction of the IBS till completion of resection.

All patient received pre-operative cervical preparation with misoprostol $400 \mathrm{mcg}$ inserted 2 hours prior to the procedure. The IBS consisting of a $6^{\circ}$ scope with a continuous flow sheath and operating channel for insertion of the mechanical shaving system was set up as described by Bigatti et al. [1]. The sheath was connected to an irrigation pump for pressure-controlled dilation of the uterine cavity and a suction pump for removal of fluid and tissue fragments. Excess fluid was collected using a drainage bag placed under the patient. We used the 24 Fr outer sheath and normal saline irrigation for all our cases. Suction pressure was set at $250 \mathrm{ml} / \mathrm{min}$ and maximum flow setting was $300 \mathrm{ml} / \mathrm{min}$ to give a maximum uterine pressure of 100 to $150 \mathrm{mmHg}$.

\section{Results}

A total of 21 cases were performed over 6 months between August 2015 and June 2016. All cases were performed by two Senior Consultant gynaecologists who had received formal training in using the intrauterine Bigatti shaver.

The majority of cases $(18,86 \%)$ were performed to resect endometrial polyps associated with menstrual abnormalities or subfertility. Number of polyps resected in each case ranged from 1 - 3 and polyp size ranged from 1 to $4 \mathrm{~cm}$. The remaining three cases were for menstrual abnormality due to a submucosal fibroid and polyp, resection of a uterine septum, and removal of retained products of conception. 
The mean time taken for device set up was 8.3 minutes (range $5-20$ ), while the mean operating time was 9.6 minutes (range 3 - 25). The median fluid input was $1450 \mathrm{mls}$ (range 700 - 3000) and the median fluid deficit was $100 \mathrm{mls}$ (range 50 - 300). For the cases involving resection of endometrial polyps only, the median operating time was 5.5 minutes (range 3 - 15). The patient characteristics and surgical details are summarized in Table 1 \& Table 2.

There were no cases of infection, uterine perforation or fluid overload. The blade of the IBS was bent after resection of the polyp in one patient with an anterior wall polyp in an anteverted uterus. Resection could not be achieved in the patient with a $3 \mathrm{~mm}$ grade 1 submucosal fibroid (FIGO classification) as the lesion was too hard in consistency, and the surgeon had to switch to conventional resectoscope to complete the procedure.

\section{Discussion}

Our series shows that the intrauterine Bigatti shaver is a safe and effective method for resection of endometrial polyps. The continuous flow of fluid and suction of tissue fragments offers a definite advantage by providing constant clear visualization. This is crucial in hysteroscopic surgery as an obscured operating field is the main reason for serious complications such as uterine perforation and prolonged surgery leading to fluid overload [1] [2]. In our series, we were able to completely resect sizeable endometrial polyps within a short operating time and with minimal fluid deficit.

There were no serious complications despite this series being the first performed by both surgeons. This suggests that the procedure has a short learning curve, especially compared to alternative methods such as the bipolar resectoscope. Mechanical resection also allows the use of normal saline and avoidance of electric current; these factors

Table 1. Patient and operative characteristics (endometrial polyps).

\begin{tabular}{cc}
\hline Number of cases & $18(86 \%)$ \\
Polyp size $(\mathrm{mm})$ & $10-40$ \\
Median resection time (min) & 5.5 \\
Median fluid input (ml) & 1450 \\
Median fluid deficit (ml) & -100 \\
Complications & 1 (Damage to IBS shaver blade) \\
\hline
\end{tabular}

Table 2. Patient and operative characteristics (others).

\begin{tabular}{ll}
\hline \multicolumn{1}{c}{ Number of cases } & \multicolumn{1}{c}{$3(14 \%)$} \\
Operative findings & $\begin{array}{l}\text { 1. Submucosal fibroid } 3 \mathrm{~mm}(\mathrm{G} 1) \text { \& polyp } 5 \mathrm{~mm} \\
\text { 2. Uterine septum } 2 \mathrm{~cm} \text { in width, occupying } 20 \% \text { of cavity } \\
\text { 3. Retained products of conception }\end{array}$ \\
Median resection time (min) & 6 \\
Median fluid input $(\mathrm{ml})$ & 2125 \\
Median fluid deficit $(\mathrm{ml})$ & -100 \\
Complications & 1 (Difficulty achieving complete resection of submucosal fibroid)
\end{tabular}


eliminate the risk of hyponatremia and diathermy burns. There is also minimal damage to the surrounding endometrium, making it an ideal approach for women undergoing polyp resection for fertility reasons.

The inner blade of the mechanical shaver was found to be bent after resection of an anterior wall polyp in an anteverted uterus. This was likely because the window of the blade had not been placed in direct contact with the tissue during the procedure. Such damage can be avoided by rotating the optic such that the operating channel lies in apposition with the uterine wall where the lesion is located and the window of the blade is in direct contact with the tissue [4]. As an example, in the case of an anterior wall polyp, the telescope should be rotated inferiorly so that the operating channel will lie anteriorly in direct contact with the lesion. Once the correct orientation has been achieved, this should be maintained throughout the procedure.

Some initial technical difficulties were encountered in relation to the instrument set up. Assembling the device took longer (up to 20 minutes) when the procedure was first introduced, however this improved with increasing familiarity with the equipment. We also found that the existing collection apparatus was unable to effectively sieve out and collect small polyp fragments. We thus fashioned a "drainage sock" out of ribbon gauze and attached this to the end of the suction tubing (Figures 1-4). This proved to be an effective and economical solution.

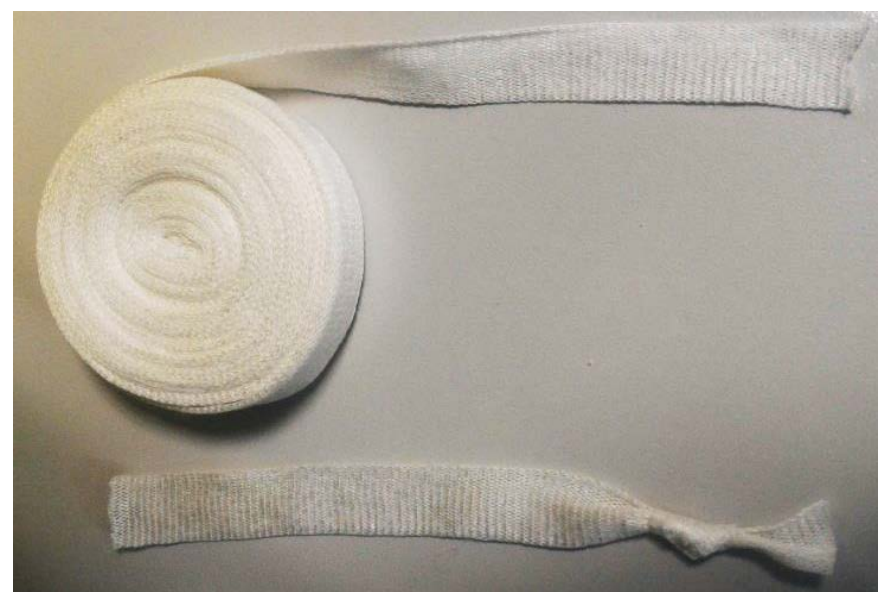

Figure 1. "Drainage sock" fashioned out of ribbon gauze.

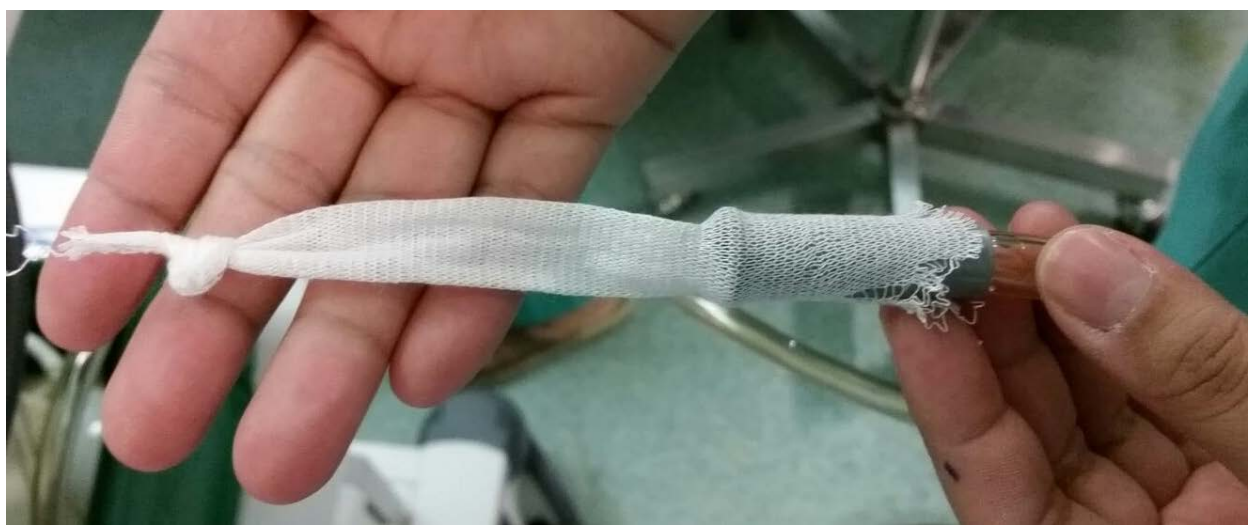

Figure 2. Sock attached to the end of the suction tubing. 


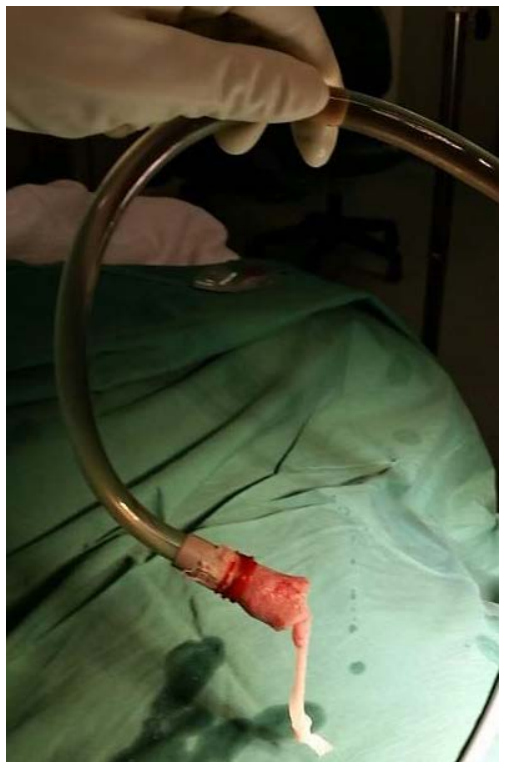

Figure 3. Sock at completion of the procedure.

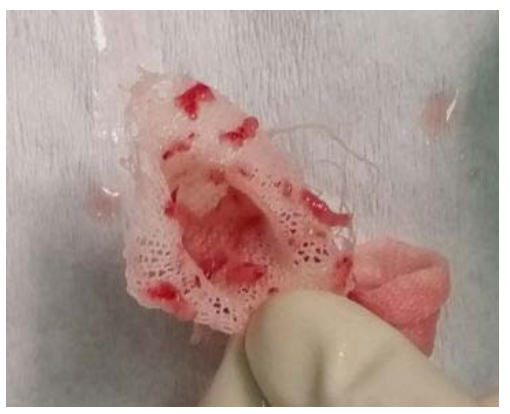

Figure 4. Sock opened up to show fragments of polyp trapped within.

Only a minority of our cases were performed for lesions other than endometrial polyps. Operating time was generally longer in these cases (Table $1 \&$ Table 2). Bigatti et al. had previously reported a successful series of hysteroscopic myomectomies [5], where he noted that it was the consistency of the myoma, more than the size or type, which appeared to be the main factor in determining the efficacy of the procedure. Our experience lends support to this theory, as we were unable to resect a submucosal fibroid with a hard consistency and had to complete the procedure using a conventional bipolar resectoscope.

The intrauterine Bigatti shaver is a valuable addition to the currently available methods for resection of endometrial polyps. In view of its safety advantages, we have started offering it as the first line of treatment for patients requiring removal of endometrial polyps in our department. Further study is required to determine the utility of the intrauterine Bigatti shaver for submucosal fibroids, particularly those with a hard consistency.

\section{References}

[1] Preutthipan, S. and Herabutya, Y. (2005) Hysteroscopic Polypectomy in 240 Premenopausal \& Postmenopausal Women. Fertility and Sterility, 83, 705-709. 
https:/doi.org/10.1016/j.fertnstert.2004.08.031

[2] Bigatti, G., Ferrario, C., Rosales, M., Baglioni, A. and Bianchi, S. (2012) IBS ${ }^{\circledast}$ Integrated Bigatti Shaver versus Conventional Bipolar Resectoscopy: A Randomised Comparative Study. Gynecological Surgery, 9, 63-72. https:/doi.org/10.1007/s10397-011-0701-9

[3] Bigatti, G. (2011) IBS $^{\circledast}$ Integrated Bigatti Shaver, an Alternative Approach to Operative Hysteroscopy. Gynecological Surgery, 8, 187-191. https:/doi.org/10.1007/s10397-010-0634-8

[4] Bigatti, G. (2016) The Shaver Technique. http://theibs.eu/IbsTips.html

[5] Bigatti, G., Franchetti, S., Rosales, M., Baglioni, A. and Bianchi, S. (2014) Hysteroscopic Myomectomy with the IBS $^{\circledast}$ Integrated Bigatti Shaver versus Conventional Bipolar Resectoscope a Retrospective Comparative Study. Gynecological Surgery, 11, 9-18.

https:/doi.org/10.1007/s10397-013-0827-z

Submit or recommend next manuscript to SCIRP and we will provide best service for you:

Accepting pre-submission inquiries through Email, Facebook, LinkedIn, Twitter, etc. A wide selection of journals (inclusive of 9 subjects, more than 200 journals) Providing 24-hour high-quality service User-friendly online submission system Fair and swift peer-review system Efficient typesetting and proofreading procedure Display of the result of downloads and visits, as well as the number of cited articles Maximum dissemination of your research work

Submit your manuscript at: http://papersubmission.scirp.org/

Or contact ojog@scirp.org 